\title{
Production and structural characterization of biosurfactant produced by newly isolated staphylococcus xylosus STF1 from petroleum contaminated soil
}

\author{
Nalan Oya San Keskin a,b, Diren Han ${ }^{\mathrm{c}}$, Alper Devrim Ozkan ${ }^{\mathrm{c}}$, Pinar Angun ${ }^{\mathrm{c}}$, \\ Ozgun Candan Onarman Umu ${ }^{\mathrm{c}}$, Turgay Tekinay ${ }^{\mathrm{b}, \mathrm{d}, *}$ \\ ${ }^{a}$ Polath Faculty of Literature and Science, Department of Biology, Gazi University, Polatl, Ankara 06900, Turkey \\ ${ }^{\mathrm{b}}$ Life Sciences Application and Research Center, Gazi University, Gölbaşı, Ankara 06830, Turkey \\ c UNAM, Institute of Materials Science and Nanotechnology, Bilkent University, Bilkent, Ankara 06800, Turkey \\ d University Faculty of Medicine, Department of Medical Biology and Genetics, Gazi University, Ankara 06560, Turkey
}

\section{A R T I C L E I N F O}

Article history:

Received 10 March 2014

Received in revised form

15 April 2015

Accepted 13 July 2015

Available online 17 July 2015

Keywords:

Biosurfactant

FT-IR

Lipopeptide

Raman spectroscopy

Staphylococcus

\begin{abstract}
A B S T R A C T
Petroleum-contaminated soil was used to isolate and characterize biosurfactant producing bacteria. The strain could produce higher amount of biosurfactant in medium supplemented with motor oil as sole source of carbon and energy. A new biosurfactant producing bacterium, designated as Staphylococcus xylosus STF1 based on morphological, physiological, biochemical tests and 16S rRNA gene sequencing. The isolated bacterium was first screened for the ability to produce biosurfactant. Partial sequence of STF1 strain of 16S rDNA gene was highly similar to those of various members of the family Staphylococcaceae. Biochemical characterizations including FT-IR, Raman spectroscopy and Mass spectroscopy studies suggested the biosurfactant to be lipopeptide. Study also confirmed that the cell free supernatant exhibited high emulsifying activity against the different hydrocarbons. Moreover, the partially purified biosurfactant exhibited antimicrobial activity by inhibiting the growth of several bacterial species. The strain could be a potential candidate for the production of polypeptide biosurfactant which could be useful in a variety of biotechnological and industrial processes, particularly in the food and oil industry. (c) 2015 Elsevier B.V. All rights reserved.
\end{abstract}

\section{Introduction}

Surfactants are amphipathic molecules capable of reducing surface and interfacial tensions between liquids, solids and gases (Desai and Banat, 1997; Banat et al., 2000; Nitschke and Costa, 2007). All surfactants have two ends, one of which is hydrophobic and the other hydrophilic (Desai and Banat, 1997). A hydrocarbon part usually comprises the hydrophobic end, which is less soluble in water, whereas the water-soluble hydrophilic end may be a carbohydrate, amino acid, cyclic peptide, phosphate, carboxylic acid or alcohol (Rahman, 2008).

The disposal of oil residues from storage, processing and transportation facilities has always been a major issue faced by the petroleum industry. As a result of increasing environmental awareness and the emphasis placed on a sustainable society in harmony with the global environment, natural surfactants of

\footnotetext{
* Corresponding author at: Life Sciences Application and Research Center, Gaz University, Golbasi, Ankara 06830, Turkey. Fax: +90 3124846271.

E-mail address: ttekinay@gazi.edu.tr (T. Tekinay).
}

microbial origin have recently been recommended to replace chemically synthesized surface active agents (Das and Mukherjee, 2007; Gusmão et al., 2010). These natural surfactants offer a number of advantages over chemical surfactants, such as adequate inherent biodegradability, low toxicity and ecological acceptability. These substances may also be used at extremes of acidity, temperature and salt concentration and can be produced from inexpensive, renewable substrates (Banat et al., 2010; Santos et al., 2013).

Biosurfactants are structurally diverse surface active agents produced mainly by hydrocarbon-utilizing bacteria, yeasts and filamentous fungi (Desai and Banat, 1997; Banat et al., 2000; Makkar and Cameotra, 2002; Rahman, 2008). Biosurfactants are utilized in commercial applications in various industries (Desai and Banat, 1997; Kosaric, 1992; Banat et al., 2000) and can be classified by their molecular weight as low-molecular-mass and high-molecular-mass polymers. Low-molecular-mass biosurfactants include glycolipids, lipopeptides and phospholipids, while high-molecularmass biosurfactants includepolymeric and particulate surfactants and may act as emulsion stabilizing agents (Nitschke and Costa, 
2007). Some of the most common biosurfactants are glycolipids, rhamnolipids, sophorolipids, trehalolipids, lipoproteins and lipopeptides, fatty acids, phospholipids and polymeric structures such as emulsan and liposan (Chrzanowski et al., 2012; Banat et al., 2010).

A great number of microorganisms are capable of secreting various types of biosurfactants. Among these, genera most commonly utilized for biosurfactant production are Pseudomonas sp., Bacillus sp., Rhodococcus sp., Candida sp., Lactobacillus sp., Arthobacter sp. and Acinetobacter sp. (Rosenberg and Ron, 1999; Banat et al., 2000; Rufino et al., 2013). While chemically synthesized surfactants are highly effective, such chemicals also tend to be toxic, hazardous to environment and difficult to degrade (Ławniczak et al., 2013). Biosurfactants are biodegradable and less toxic compared to conventional surfactants and as such do not threaten the environment to the same extent as the latter (Vasileva-Tonkova et al., 2011). As such, biosurfactants offer a more environmentally friendly alternative to conventional surfactants (Jacques et al., 2005; Boonchan et al., 1998; Miguel et al., 2009).

Further, biosurfactants are biocompatible, easily degraded in the environment and specific in their action due to the presence of specific functional groups (Bharali et al., 2011). In addition, biosurfactants have better foaming properties, are stable in extreme $\mathrm{pH}$, temperature and salinity ranges (Banat et al., 2000) and can be produced by processing of as industrial wastes or by-products as a nutrient source to biosurfactant-producing microorganisms (Kosaric, 1992).

Biosurfactants have several industrial applications (Cameotra and Bollag, 2003; Soudmand-asali et al., 2007; Ferhat et al., 2011). In addition to their extensive utilization for enhanced oil recovery and bioremediation of pollutants, (Chrzanowski et al., 2012; Szulc et al., 2014; Xiao et al., 2012) surface tension-reducing biological agents have potential application areas in agriculture, detergents, cosmetics, personal care products, pharmaceuticals, textile manufacturing, laundry supplies, metal treatment and processing, pulp and paper processing and paint industries. Further, biosurfactants can be used in food industry as emulsifiers, solubilizers, foaming, wetting, anti-adhesive and antimicrobial agents (Singh and Cameotra, 2004).

In the light of the literatures, present study is the first study about the production of a biosurfactant from the bacteria Staphylococcus xylosus which isolated from petroleum contaminated soil. The properties of the biosurfactant produced with different oils and the effect of environmental factors on emulsification activity and stability are reported.

\section{Materials and methods}

\subsection{Isolation, identification and culture conditions of microorganism}

The biosurfactant producing bacteria were isolated from the petroleum contaminated soil samples of Ankara, Turkey $\left(39.8679^{\circ} \mathrm{N}, 32.7489^{\circ} \mathrm{E}\right)$. Soil samples were collected from the surface layer $(5-15 \mathrm{~cm})$ and transported aseptically in a sterile plastic container to the laboratory; they were air dried and stored at $4{ }^{\circ} \mathrm{C}$ until use. Cultures were grown in Mineral Salt Medium (MSM) with $15 \mathrm{~W}-40$ motor oil as the sole source of carbon and energy and incubated at $125 \mathrm{rpm}$ and $30^{\circ} \mathrm{C}$. Cultures were stored at $4{ }^{\circ} \mathrm{C}$ to maintain viability. For long-term storage, cultures were maintained at $-80{ }^{\circ} \mathrm{C}$ in $20 \%$ glycerol.

Identification of biosurfactant producing bacterium was done by Scanning Electron Microscopy (SEM), 16S rDNA technology and cultural characterization. Partial 16S rDNA gene sequencing was done at ABI 3130xl analyzer based on Sanger's dideoxy termination method at the REFGEN, Ankara, Turkey. The 16S rDNA sequence is available under the GenBank accession number: KP162129. The sequences obtained were analyzed using BLAST. The strain was kept at the public culture collection of the Sustainable Energy Laboratory (SUELab) of Gazi University, (Ankara, Turkey). Cell morphologies were examined under a scanning electron microscope (SEM; JSM-6390, JEOL, Japan) with 20,000 V accelerating voltage.

\subsection{Preparation of the bacterial inocula}

To screen the isolated bacteria for biosurfactant production, a single colony of each isolate was inoculated into $5 \mathrm{ml}$ of MSM in tubes and incubated overnight until an $\mathrm{OD}_{580}$ of 1.5 was reached. These cultures were used as inocula for the screening cultures. In all screening assays, uninoculated growth medium was used as a negative control.

\subsection{Screening for biosurfactant production}

\subsubsection{Hemolytic activity}

The bacterium was tested for the ability to produce biosurfactant by using hemolytic assay as the method described by Youssef et al. (2009) with slight differences. Overnight culture of S. xylosus STF1 grown on LB medium was inoculated as $10 \mu \mathrm{l}$ spots on $5 \%$ human blood agar plates and incubated at $30^{\circ} \mathrm{C}$ for $24 \mathrm{~h}$ and then observed for the zone of hemolysis around the spot.

\subsubsection{Drop-collapse oil assay}

Biosurfactant production was screened using the qualitative drop-collapse oil test described by Bodour et al. (1998) with slight modifications. $2 \mu \mathrm{L}$ of $15 \mathrm{~W}-40$ motor oil was dropped at the center of each well on a 96-well micro-titer plate and allowed to stand for $24 \mathrm{~h}$ for equilibration. $5 \mu \mathrm{L}$ aliquot of sample was dropped on the oil-coated wells and then the drop size was observed after 1 min with the help of a magnifying glass. The beaded drop was recorded as negative, indicating that the microorganism tested does not produce biosurfactant. Collapsed drops were taken as indicative of biosurfactant production.

\subsubsection{Atomized oil assay}

In order to determine the levels of biosurfactant production, the atomized oil assay was performed as described in Burch et al. (2010). Bacteria were spotted onto LB agar plates and, following growth, incubated with open lids for drying. A fine mist of mineral oil was applied onto the plates by an airbrush with an air pressure of $15-30$ psi. Pressure settings were optimized in order to apply a uniform and controlled stream of oil droplets. Biosurfactant halos were observed immediately following oil application by an indirect bright light source, halo diameters were measured and recorded.

\subsubsection{Emulsification index measurement}

Emulsification index measurement was adapted from the method described by Youssef et al. (2009). Hydrocarbons such as waste motor lubricant oil, crude oil, diesel, kerosene, naphthalene, anthracene, xylene, and peanut oil were tested for emulsification activity. Cell free supernatants were mixed vigorously with the tested oils in a 1:1 ratio. Tubes containing the mixture were then left undisturbed for $24 \mathrm{~h}$. The emulsification index (E24) was calculated as the percentage of height of the emulsion layer divided by the total height.

\subsubsection{Antimicrobial test}

The bacterial species Bacillus subtilis (ATCC 6633), Staphylococcus aureus (RSHM 25923), Klebsiella pneumonia, Pseudomonas aeruginosa and Escherichia coli DH5 were obtained from the 
Institute of Materials Science and Nanotechnology, Bilkent University, Turkey. Antimicrobial activity assay was adapted from the method described by Rojas et al. (1992). Overnight incubated cultures of the isolates were horizontally streaked onto LB agar and incubated at $30{ }^{\circ} \mathrm{C}$ for $48 \mathrm{~h}$. After the incubation period, the plates were exposed to chloroform vapors for $90 \mathrm{~min}$ for the inactivation of active cells. The plates were aerated for 20 min to completely remove the residual chloroform by vaporization and the plate covers were changed following aeration. Selected pathogens were then streaked vertically on the horizontal streaked cells and plates were incubated at $30^{\circ} \mathrm{C}$ for $24 \mathrm{~h}$. The inhibition on the growth line of pathogens was measured as indicative of antimicrobial activity.

\subsubsection{Biosurfactant recovery}

Scale up of biosurfactant production was performed in a $30 \mathrm{~L}$ bioreactor (Sartorius, Germany), containing $20 \mathrm{~L}$ production medium. The culture medium was inoculated with a $24 \mathrm{~h}$ inoculum. The bioreactor was kept under $150 \mathrm{rpm}$ orbital agitation at $30^{\circ} \mathrm{C}$. After large-scale production, the surfactant was precipitated from cell-free supernatant of the culture by adjusting the $\mathrm{pH}$ to 2.0 using $6 \mathrm{~N} \mathrm{HCl}$. The supernatant was then left at $4{ }^{\circ} \mathrm{C}$ overnight. After overnight incubation, precipitated material was collected by centrifugation at $11,000 \mathrm{~g}$ for $20 \mathrm{~min}$. The crude biosurfactant was then be lyophilized and weighed for quantification. For the extraction of biosurfactant compounds, chloroform methanol was added to the dry product and incubated at $250 \mathrm{rpm}$, $30{ }^{\circ} \mathrm{C}$ for $15 \mathrm{~min}$. The mixture was filtrated using a $0.45 \mathrm{~mm}$ Millipore membrane and the filtrate was collected for analysis.

Biosurfactant is purified by using preparative HPLC system. A Zorbax Eclipse column XDB C18 (21.2 mm diameter, $150 \mathrm{~mm}$ length) was used for the separation and the column flow rate was set to $15 \mathrm{~mL} / \mathrm{min}$. Solvents used were $98 \%$ water with $0.05 \%$ formic acid and 2\% Methanol containing \% 0.05 formic acid.

\subsection{Characterization of the purified biosurfactant}

\subsubsection{Mass spectrometric analysis}

The mass spectroscopic analysis of the biosurfactant was carried out in a mass spectrometer (Agilent Technologies 6530 accurate-Mass Q-TOF LC/MS) utilizing electro spray ionization (ESI). The standard solutions to be analyzed were introduced by direct infusion with a syringe pump at a flow rate of $0.3 \mathrm{~mL} / \mathrm{min}$ in the ESI. Negative ion mode was used and scanning was performed at $100-2000 \mathrm{~m} / \mathrm{z}$ range. The voltage of the capillary was $3.5 \mathrm{kV}$.

\subsubsection{Fourier transform infrared spectroscopy}

Biosurfactant was put onto the FTIR plate and left to dry at $70{ }^{\circ} \mathrm{C}$ for $1 \mathrm{~h}$. The IR spectrum was recorded on Nicolet 6700 FTIR, Thermo Scientific. The IR spectra were collected from 400-4000 wave number $\left(\mathrm{cm}^{-1}\right)$.

\subsubsection{Raman spectroscopy}

In biological and chemical systems, Raman spectroscopy has been used successfully to characterize the structural conformation, functionalities, and molecular composition of lipid bilayers and surfactant mono and bilayers, including the interdigitization of lipid and surfactant chains or tail groups in bilayers (Dendramis et al., 1983, Levin et al., 1990; Vincent et al., 1991; Suga et al., 1995; Suna et al. 2013). Raman spectra were acquired at room temperature by using a Witec Alpha300S+Raman Module. A solidstate $532 \mathrm{~nm}$ wavelength laser was used for excitation in Raman measurements single spectra were taken under 50x magnification and $2.03 \mathrm{~s}$ integration times.

\section{Results and discussion}

Bacterial strains isolated from soil sources were screened for biosurfactant production by drop collapse oil assay and one of the tested strains was observed to demonstrate rapid drop collapse activity and high biosurfactant production. This strain was selected for biosurfactant characterization and is henceforth called STF1.

After demonstration of STF1's biosurfactant activity, genotypic analysis on the basis of partial 16S rRNA sequencing was performed to determine the precise taxonomic position of the strain (Fig. 1). Molecular data shows that new isolate STF1 is similar to NR036907 Staphylococcus xylosus KL162. As a result a newly isolated bacterium is Staphylococcus xylosus STF1 (GenBank Accession No. KP162129).

Morphological characteristics were observed under SEM for further identification (Fig. 2). As seen in Fig. 2, Staphylococcus $x y$ losus STF1 are perfectly spherical cells.

When dropped onto blood agar, S. xylosus STF1 cells showed hemolytic activity and produced clear zones around the droplets (Fig. 3). Walter et al. (2010) previously demonstrated that biosurfactants can cause hemolysis. However, it must be noted that the hemolytic activity method is not specific to surfactants and the reason of the clear zones might also be various lytic enzymes produced by bacteria.

A surfactant-containing liquid drop will completely spread over the surface of oil because of the decrease in surface tension in the liquid - liquid interface (Youssef et al., 2004). A drop of S. xylosus STF1 culture supernatant collapsed on motor oil, confirming the biosurfactant production (Fig. 4b), while the supernatant of $E$. coli culture, which was used as negative control, remained unaltered (Fig. 4a). In addition, side views of the droplets from supernatant of E. coli (Fig. 4d) and supernatant of STF1 on motorine (Fig. 4e) are also provided.

Contact angle measurement system was also used to better observe and quantify the collapse of droplets on the oil surface. Results demonstrate that while the droplet from the supernatant of $E$. coli retailed a high contact angle throughout the experiment, the droplet from the supernatant of S. xylosus STF1 had collapsed in a short time period. Contact angle of supernatants after $41 \mathrm{~h}$ were $46.5^{\circ}$ and $5.7^{\circ}$ for E.coli and S. xylosus STF1, respectively.

The atomized oil assay can detect a wide variety of surfactants. While this new assay readily detected a variety of both lipopeptides and glycolipids of bacterial origin, we tested the behaviors of other types of surfactants with this procedure. A variety of

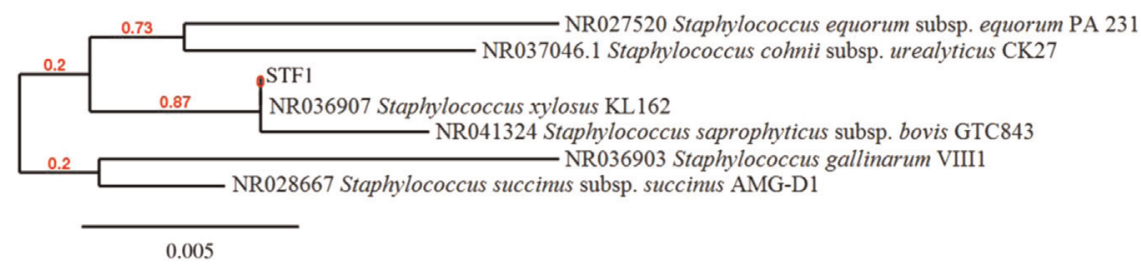

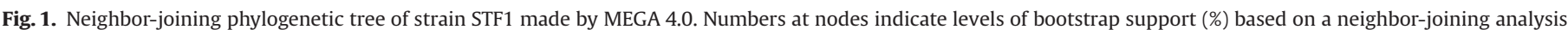
of 1000 resampled datasets; only values $>50 \%$ are given. NCBI accession numbers are given in parentheses. Bar, 0.005 nucleotide substitutions per site. 

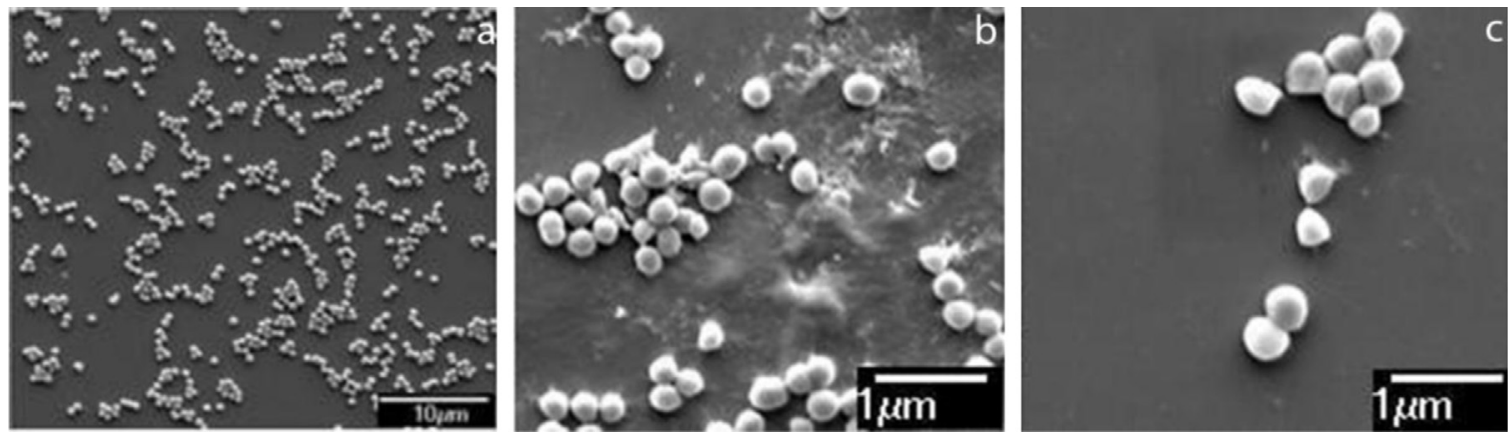

Fig. 2. Scanning electron microscopy images of Staphylococcus xylosus STF1.

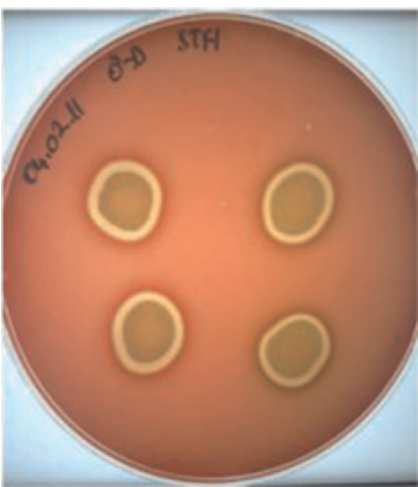

Fig. 3. Hemolytic activity result of Staphylococcus xylosus STF1.

commercially available surfactants were detectable by this assay. Fig. 5 shows that halo diameter continued to increase with time, although the rate slowed considerably after about $44 \mathrm{~h}$. Because of this, in addition to the fact that the bacteria continue to multiply and that the production of many biosurfactants is regulated by cell density, we concluded that halo measurements could not be used to calculate the absolute amount of surfactant produced by a colony without further investigation.

Fig. 6 shows emulsification activity of S. xylosus STF1 biosurfactant on various oils. Mixing of the S. xylosus STF1 supernatant and various oils resulted in the formation of an emulsified layer approximately half the height of the whole mixture. Since oil constituted half of the prepared mixture, it can be concluded that oil was emulsified entirely. These emulsions were stable for three weeks. The ability of the S. xylosus STF1 biosurfactant to form stable emulsions with vegetable oil show that the surfactant in question can be used as a cleaning and emulsifying agent in food industry. Daverey and Pakshirajan (2009) also found that emulsification activity with the soybean oil. The surfactant may also be used to prevent hydrocarbon pollution, since it can also emulsify chemicals such as benzene. No emulsified layer formation was observed in the $E$. coli culture supernatant utilized as negative control.
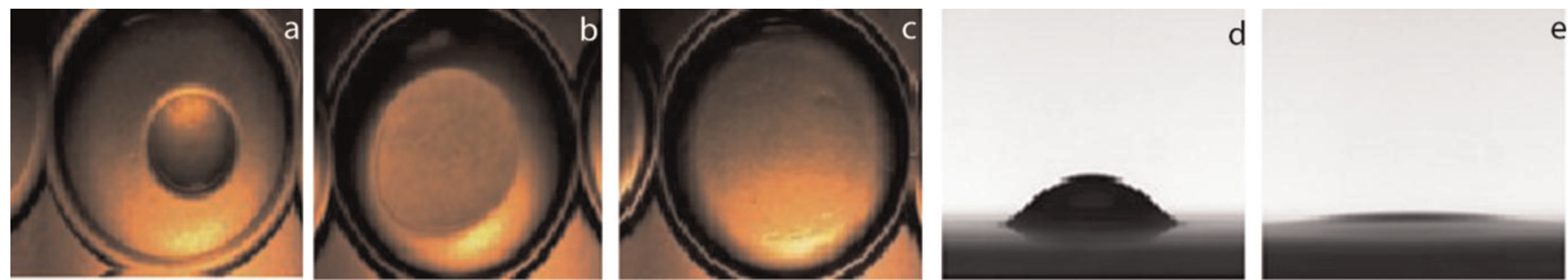

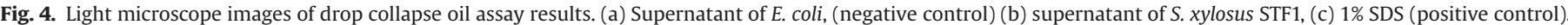
Side views of the droplets from (d) supernatant of E. coli and (e) supernatant of S. xylosus STF1 on motorine are also provided.
Fig. 5. Surfactant production by S. xylosus STF1 detected with an atomized oil assay.

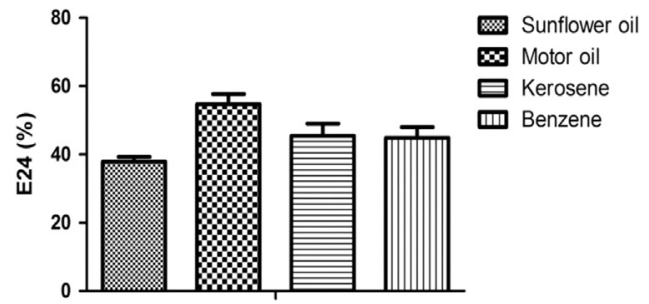

Fig. 6. Emulsification activity of S. xylosus STF1 biosurfactant on various oils.

Several biosurfactants which exhibit antimicrobial activity against various microorganisms have been previously described. They include surfactin and iturin produced by $B$. subtilis strains (Ahimou et al., 2000), rhamnolipids from Pseudomonas species (Abalos et al., 2001), and biosurfactants produced by some fungi (Arutchelvi et al., 2008). However, there are few reports about the antimicrobial activity of biosurfactants isolated from Staphylococcus. Table 1 indicated that biosurfactant of S. xylosus STF1 exhibits anti-microbial activity against various bacterial pathogens, though its efficiency differs greatly depending on the species tested. The purified biosurfactant can be recommended as a therapeutic agent or as a food additive.

For the recovery of biosurfactant, S. xylosus STF1 was grown in 30-L bioreactor and the biosurfactant was collected by foam fractionation. Biosurfactants tend to concentrate on the foam due 
Table 1

Antimicrobial effects of biosurfactant produced by S. xylosus STF1 bacteria against several bacteria.

\begin{tabular}{ll}
\hline Salmonella enterica & \pm \\
Staphylococcus aureus (RSHM 25923) & \pm \\
Bacillus subtilis (ATCC 6633) & + \\
Escherichia coli DH5 & + \\
Klebsilla pneumonia & ++ \\
Pseudomonas aeruginosa & \pm++ \\
\hline
\end{tabular}

to the surface activity, and this property has been utilized to partially purify biosurfactants of economic importance. As such, foam formed by S. xylosus STF1 was filter sterilized and the biosurfactant was separated by the use of a preparative HPLC system (data was not shown). Samples were collected from HPLC vials and tested for biosurfactant activity. Samples capable of yielding lower contact angles and higher spread rates in drop collapse oil tests were collected from HPLC and characterized by mass spectrometry and FT-IR.

Under the current experimental conditions, most spectral peaks observed were in the mass range of $m / z 120-1200 \mathrm{Da}$. As seen in Fig. 7, mass peak of the purified biosurfactant sample was at $930.9550(\mathrm{~m} / \mathrm{z})$.

The FT-IR spectroscopy was used to elucidate the molecular components of the isolated biosurfactant and the same is presented in Fig. 8. The peak at $3484 \mathrm{~cm}^{-1}$ is due to the presence of $\mathrm{N}-\mathrm{H}$ stretching and corresponds to peptide groups, while the $\mathrm{C}-\mathrm{H}$ stretching observed in the range $2726 \mathrm{~cm}^{-1}$ indicates the presence of aliphatic chains. The peak at $1741 \mathrm{~cm}^{-1}$ is the characteristic band for ester compounds. The peak observed at $1602 \mathrm{~cm}^{-1}$ is due to the presence of $\mathrm{N}-\mathrm{H}$ bond, indicating the peptide character. $\mathrm{C}-\mathrm{N}$ stretch and $=\mathrm{CH}_{2}$ bond were indicated by bands at $1085 \mathrm{~cm}^{-1}$ and $954 \mathrm{~cm}^{-1}$, respectively. In addition the bands at $804 \mathrm{~cm}^{-1}$ and $686 \mathrm{~cm}^{-1}$ indicate the presence of $\mathrm{C}-\mathrm{H}$ bending. These results show the lipopeptide presence in the biosurfactant isolated from S. xylosus STF1.

Raman scattering has traditionally been used as a vibrational spectroscopy technique complementary to infrared spectroscopy for composition analysis. It has a key advantage when applied to biological samples due to its low sensitivity to water content (Han et al. 2012). Raman spectroscopy was also utilized in order to obtain information on the composition of the biosurfactant. The Raman spectrum (Fig. 9) yielded peaks at $549 \mathrm{~cm}^{-1}$ and $789 \mathrm{~cm}^{-1}$, which indicate $(S-S)$ vibration and $(C-S)$ vibration of aliphatic chains, respectively. The peak at $1058 \mathrm{~cm}^{-1}$ shows the presence of $(\mathrm{C}-\mathrm{C})$ stretching vibrations, indicating lipid presence. The $897 \mathrm{~cm}^{-1}$ peak is associated with $(\mathrm{O}-\mathrm{O})$ stretching and $987 \mathrm{~cm}^{-1}$ peak is interpreted as (CC) alicyclic/aliphatic chain vibrations.

Another peak is observed at $1446 \mathrm{~cm}^{-1}$ and corresponds to alkyl $\mathrm{C}-\mathrm{H}_{2}$ bends present in lipids. Protein-associated vibrations

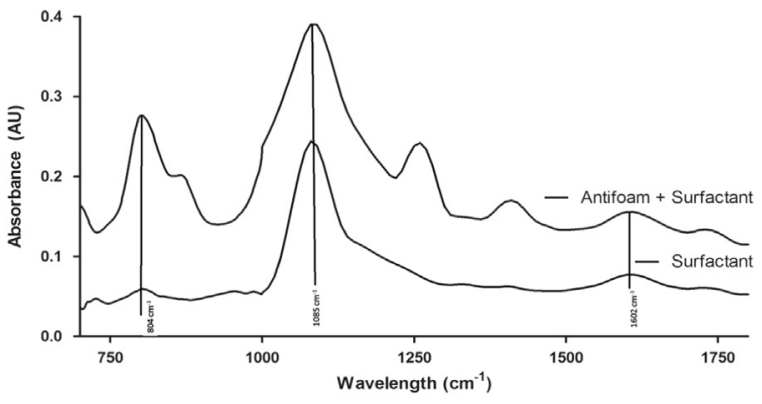

Fig. 8. FT-IR spectrum of the purified biosurfactant sample.

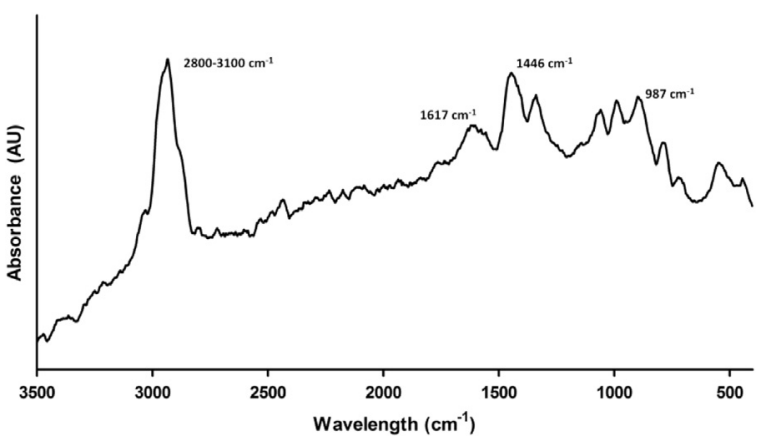

Fig. 9. Raman spectrum of the purified biosurfactant sample.

associated with nitrogen bonds were also detected at $1338 \mathrm{~cm}^{-1}$ and at $1617 \mathrm{~cm}^{-1}$, which correspond to amide III and amide I peaks, respectively. These bands are indicators of peptides. Particularly, the region between 3100 and $2800 \mathrm{~cm}^{-1}$ was used to examine the acyl or alkyl chain $\mathrm{C}-\mathrm{H}$ stretching mode region to show bilayer perturbations (Vincent et al. 1991; Suga et al., 1995).

\section{Conclusions}

In the present investigation, Staphylococcus xylosus STF1, a new lipopeptide-producing bacterium was isolated from soil contains motor oil. Although few interests were given to Staphylococcus as a biosurfactant producer, we found that biosurfactant produced by a Staphylococcus xylosus STF1 was complex structure of proteins and lipids. The isolated biosurfactant was analyzed by FT-IR, MS and Raman spectroscopy. The lipopeptide produced have ability to emulsify different hydrocarbon substrates. Although several studies on biosurfactants produced by Staphylococcus have been performed, little is known about their chemical structure, due to their complexity.

A remarkable inquiry is that when these natural surface active compounds find a proper place in a number of industries. The economic and practical progress of action is to use a careful

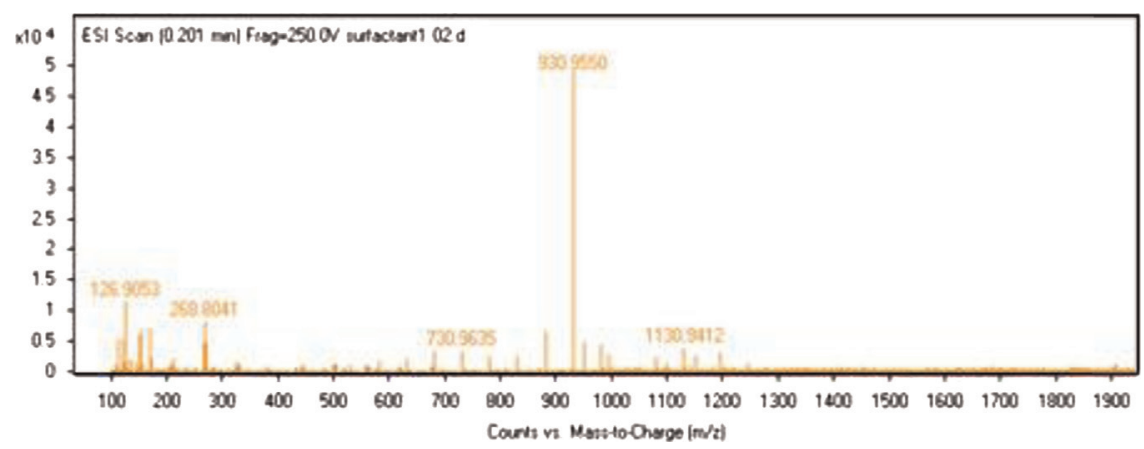

Fig. 7. Mass spectrum of the purified biosurfactant sample. 
combination of potent biosurfactant-producing bacterial strains with inexpensive and alternative substrates, to produce large amount of these microbial natural products with better quality than those of synthetic products.

\section{References}

Abalos, A., Pinazo, A., Infante, M.R., Casals, M., García, F., Manresa, A., 2001. Physicochemical and antimicrobial properties of new rhamnolipids produced by Pseudomonas aeruginosa AT10 from soybean oil refinery wastes. Langmuir 17 (5), 1367-1371.

Ahimou, F., Jacques, P., Deleu, M., 2000. Surfactin and iturin A effects on Bacillus subtilis surface hydrophobicity. Enzyme Microb. Technol. 27 (10), 749-754.

Arutchelvi, J.I., Bhaduri, S., Uppara, P.V., Doble, M., 2008. Mannosylerythritol lipids: a review. J. Ind. Microbiol. Biotechnol. 35 (12), 1559-1570.

Banat, I., Makkar, R., Cameotra, S., 2000. Potential commercial applications of microbial surfactants. Appl. Microbiol. Biotechnol. 53, 495-508.

Banat, I., Franzetti, A., Gandolfi, I., Bestetti, G., Martinotti, M., Fracchia, L., Smyth, T., Marchant, R., 2010. Microbial biosurfactants production, applications and future potential. Appl. Microbiol. Biotechnol. 87, 427-444.

Bharali, P., Das, S., Konwar, B.K., Thakur, A.J., 2011. Crude biosurfactant from thermophilic Alcaligenes faecalis: feasibility in petro-spill bioremediation. Int. Biodeterior. Biodegrad. 65, 682-690.

Bodour, A., Miller-Maier, R., 1998. Application of a modified drop-collapse technique for surfactant quantitation and screening of biosurfactant-producing microorganisms. J. Microbiol. Methods 32, 273-280.

Boonchan, S., Britz, M.L., Stanley, G.A., 1998. Surfactant-enhanced biodegradation of high molecular weight polycyclic aromatic hydrocarbons by Stenotrophomonas maltophilia. Biotechnol. Bioeng. 59, 482-494.

Burch, A., Shimada, B., Browne, P., Lindow, S., 2010. Novel high-throughput detection method to assess bacterial surfactant production. Appl. Environ. Microbiol. 76, 5363-5372.

Cameotra, S.S., Bollag, J.M., 2003. Biosurfactant-enhanced bioremediation of polycyclic aromatic hydrocarbons. Crit. Rev. Env. Sci. 33, 111-126.

Chrzanowski, Ł., Dziadas, M., Ławniczak, Ł., Cyplik, P., Białas, W., Szulc, A., Lisiecki, P., Jelen, H., 2012. Biodegradation of rhamnolipids in liquid cultures: effect of biosurfactant dissipation on diesel fuel/B20 blend biodegradation efficiency and bacterial community composition. Bioresour. Technol. 111, 328-335.

Chrzanowski, L., Ławniczak, L., Czaczyk, K., 2012. Why do microorganisms produce rhamnolipids? World J. Microbiol. Biotechnol. 28, 1-9.

Das, K., Mukherjee, A.K., 2007. Comparison of lipopeptide biosurfactants production by Bacillus subtilis strains in submerged and solid state fermentation systems using a cheap carbon source: some industrial applications of biosurfactants. Process. Biochem. 42, 1191-1199.

Daverey, A., Pakshirajan, K., 2009. Production of sophorolipids by the yeast Candida bombicola using simple and low cost fermentative media. Food Res. Int. 42, 499-504.

Dendramis, A.L., Schwinn, E.W., Sperline, R.P., 1983. A surface-enhanced Raman scattering study of CTAB adsorption on copper. Surf. Sci. 134, 675-688.

Desai, J., Banat, I., 1997. Microbial production of surfactants and their commercial potential. Microbiol. Mol. Biol. Rev. 61, 47-64.

Ferhat, S., Mnif, S., Badis, A., Eddouaouda, K., Alouaoui, R., Boucherit, A., Mhiri, N., Moulai-Mostefa, N., Sayadi, S., 2011. Screening and preliminary characterization of biosurfactants produced by Ochrobactrum sp 1C and Brevibacterium sp 7G. Int. Biodeterior. Biodegrad. 65, 1182-1188.

Gusmão, C.A.B., Rufino, R.D., Sarubbo, L.A., 2010. Laboratory production and characterization of a new biosurfactant from Candida glabrata UCP1002 cultivated in vegetable fat waste applied to the removal of hydrophobic contaminant. World J. Microbiol. Biotechnol. 26, 1683-1692.

Han, X.X., Zhao, B., Ozaki, Y., 2012. Label-free detection in biological applications of surface-enhanced Raman scattering. Trends Anal. Chem. 38, 1683-1689.

Jacques, R.J., Santos, E.C., Bento, F.M., Perlaba, M.C., Selbach, P.A., Sa, E.L., Camargo, F. A., 2005. Anthracene biodegradation by Pseudomonas sp. isolated from a petrochemical sludge landfarming site. Int. Biodeterior. Biodegrad. 56, 143-150.

Kosaric, N., 1992. Biosurfactants in industry. Pure Appl. Chem. 64, 1731-1737.

Ławniczak, L., Marecik, R., Chrzanowski, L., 2013. Contributions of biosurfactants to natural or induced bioremediation. Appl. Microbiol. Biotechnol. 97, 2327-2339.

Levin, I.W., Lewis, E.N., 1990. Fourier transform Raman spectroscopy of biological materials. Anal. Chem. 62 (21), 1101-1111.

Makkar, R., Cameotra, S., 2002. An update on the use of unconventional substrates for biosurfactant production and their new applications. Appl. Microbiol. Biotechnol. 58, 428-434.

Nitschke, M., Costa, S., 2007. Biosurfactants in food industry. Trends Food Sci. Technol. 18, 252-259.

Rahman, P.K.S.M., 2008. Production, characterisation and applications of biosurfactants-review. Biotechnology 7, 360-370.

Rojas, A., Hernandez, L., Pereda-Miranda, R., Mata, R., 1992. Screening for antimicrobial activity of crude drugs and pure natural products from Mexican medicinal plants. J. Ethnopharmacol. 35, 275-283.

Rosenberg, E., Ron, E., 1999. High- and low-molecular-mass microbial surfactants. Appl. Microbiol. Biotechnol. 52, 154-162.

Rufino, R.D., Luna, J.M., Marinho, P.H.C., Farias, C.B.B., Ferreira, S.R.M., Sarubbo, L.A. 2013. Removal of petroleum derivative adsorbed to soil by biosurfactant Rufisan produced by Candida lipolytica. J. Pet. Sci. Eng. 109 (2013), 117-122.

San Miguel, V., Peinado, C., Catalina, F., Abrusci, C., 2009. Bioremediation of naphthalene in water by Sphingomonas paucimobilis using new biodegradable surfactants based on poly ( $\varepsilon$-caprolactone). Int. Biodeterior. Biodegrad. 63, 217-223.

Santos, D.K.F., Rufino, R.D., Luna, J.M., Santos, V.A., Salgueiro, A.A., Sarubbo, L.A., 2013. Synthesis and evaluation of biosurfactant produced by Candida lipolytica using animal fat and corn steep liquor. J. Pet. Sci. Eng. 105, 43-50.

Soudmand-asali, A., Ayatollahi, S., Mohabatkar, H., Zareie, M., Shariatpanahi, F., 2007. The in situ microbial enhanced oil recovery in fractured porous media. J. Pet. Sci. Eng. 58, 161-172.

Singh, P., Cameotra, S., 2004. Potential applications of microbial surfactants in biomedical sciences. Trends Biotechnol. 22, 142-146.

Suga, K., Bradley, M., Rusling. J.M., 1995. Probing the interface of cast surfactant films and an underlying metal by surface-enhanced Raman scattering spectroscopy. Langmuir 9, 3063-3066.

Suna, Z., Park, Y., Zheng, S., Ayoko, G.A., Frost, R.L., 2013. Thermal stability and hotstage Raman spectroscopic study of Ca-montmorillonite modified with different surfactants: a comparative study. Thermochim. Acta 569, 151-160.

Szulc, A., Ambrozewicz, D., Sydow, M., Ławniczak, Ł., Piotrowska-Cyplik, A., Marecik, R., Chrzanowsk, Ł., 2014. The influence of bioaugmentation and biosurfactant addition on bioremediation efficiency of diesel-oil contaminated soil: feasibility during field studies. J. Environ. Manage. 132, 121-128.

Vasileva-Tonkova, E., Sotirova, A., Galabova, D., 2011. The effect of rhamnolipid biosurfactantp by Pseudomonas fluorescens on model bacterial strains and isolates from industrial wastewater. Curr. Microbiol. 62, 427-433.

Vincent, J.S., Levin, I.W., 1991. Raman spectroscopic studies of dimyristoylphosphatidic acid and its interactions with ferricytochrome c in cationic binary and ternary lipid-protein complexes. Biophys. J. 59, 1007-1021.

Walter, V., Syldatk, C., Hausmann., R., 2010. Screening concepts for the isolation of biosurfactant producing microorganisms. Biosurfactants 672, 1-13.

Xiao, X., Chen, H., Si, Wu, L., 2012. Influence of biosurfactant-producing strain Bacillus subtilis BS1 on the mycoremediation of soils contaminated with phenanthrene. Int. Biodeterior. Biodegrad. 75, 36-42.

Youssef, N.H., Duncan, K.E., Nagle, D.P., Savage, K.N., Knapp, R.M., 2004. Comparison of methods to detect biosurfactant production by diverse microorganisms. J. Microbiol. Methods 56, 339-347.

Youssef, N., Elshahed, M.S., Mc Inerney, M.J., 2009. Microbial processes in oil fields: culprits, problems, and opportunities. Adv. Appl. Microbiol. 66, 141-251. 